Pathologe 2019 40 (Suppl 3):S407-S408 https://doi.org/10.1007/s00292-019-00708-4 Online publiziert: 11 . November 2019

(c) Springer Medizin Verlag GmbH, ein Teil von Springer Nature 2019
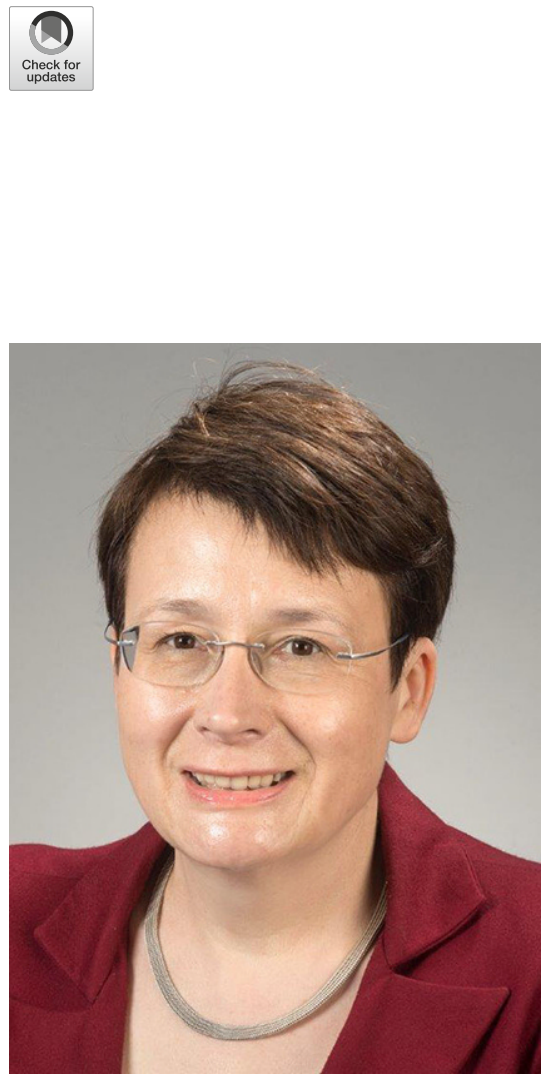

Katrin Friedrich

Am 18.01.2019 verstarb gerade einmal 55-jährig Frau PD Dr. Katrin Friedrich nach schwerer Erkrankung in Dresden. Die große Anteilnahme, die ihr Tod im Institut für Pathologie des Universitätsklinikums Carl Gustav Carus an der TU Dresden und weit darüber hinaus ausgelöst hat, zeigt, welche Akzeptanz und Beliebtheit sie sich in ihrem Beruf als Pathologin erworben hatte.

Frau Friedrich hat vieles auf sich genommen, um sich den Wunsch zu erfüllen, Ärztin zu werden. Nach Abschluss der polytechnischen Oberschule hat sie zunächst eine Ausbildung zur Krankenschwester absolviert und einige Zeit in diesem Beruf gearbeitet. Parallel dazu hat sie den Abiturkurs an der Volkshochschule besucht. Schließlich konnte sievon 1986 bis 1992 in Berlin und Dresden Medizin studieren.

\title{
G. Baretton
}

Institut für Pathologie, Universitätsklinikum Carl Gustav Carus, Technische Universität Dresden, Dresden, Deutschland

\section{Katrin Friedrich}

\subsubsection{3-18.01.2019}

Nach der Diplomarbeit 1992 zeigte sich schon am Thema ihrer Promotion ihr besonderes Interesse am Fach Pathologie, speziell der Mamma- und Gynäkopathologie: Es ging um immunhistologische Untersuchungen am invasiv-duktalen Mammakarzinom.

Von 1992 bis 1999 war sie als Assistenzärztin im Dresdner Universitätsinstitut tätig, Ende 1999 legte sie erfolgreich die Facharztprüfung ab.

In der Arbeitsgruppe ihres Doktorvaters, Herrn Prof. Dr. med. habil. D. Kunze, blieb sie auch nach der Promotion weiter wissenschaftlich aktiv. Sie hat sich intensiv mit DNA-Zytometrie am Mammakarzinom und später auch mit modernen molekularen Methoden wie der Fluoreszenz-in-situ-Hybridisierung (FISH) und der komparativen genomischen Hybridisierung (CGH) beschäftigt. Im Oktober 1996 und März 1997 verbrachte sie mit einem Stipendium der Nationalen Akademie der Wissenschaften Leopoldina (Leopoldina Förderpreis) einen Forschungsaufenthalt am National Genome Research Institute im Labor von Prof. Dr. Th. Ried (National Institutes of Health/NIH, Bethesda, MD, USA).

$\mathrm{Zu}$ dieser Zeit bin ich Frau Friedrich zum ersten Mal auf wissenschaftlichen Symposien und Tagungen begegnet, da wir die gleichen Forschungsinteressen und methodischen Schwerpunkte hatten. Als ich im Oktober 2000 die Leitung des Dresdner Universitätsinstituts übernommen habe, war ich froh, in ihr eine hoch motivierte und wissenschaftlich interessierte Fachärztin vorzufinden, die mich bei der Restrukturierung des Instituts in der Krankenversorgung und in der Forschung kompetent unterstützt hat. Aufgrund ihrer hohen fachlichen Kompe- tenz und menschlichen Integrität wurde sie 2002 zur Oberärztin ernannt.

Im Jahr 2012 habilitierte sie an der Medizinischen Fakultät Carl-Gustav-Carus derTU Dresden zum Thema „Chromosomale Imbalancen in der Progression invasiver Mammakarzinome“. Sie hat zahlreiche Promovenden betreut und sich sehr in der Lehre engagiert.

Während dieser Jahre entwickelte sie sich zu einer renommierten, exzellenten Mamma- und Gynäkopathologin. Ein national sichtbarer Beleg ihrer diagnostischen Fähigkeiten war der von ihr gemeinsam mit Prof. Dr. St. Hauptmann durchgeführte und hervorragend evaluierte IAP-Kurs zu Stromatumoren des Ovars.

All dies dokumentiert, wie konsequent und pragmatisch ihr Tun und Handeln stets war.

Dies galt aber nicht nur für ihren $\mathrm{Be}$ ruf, sondern auch für die Verfolgung ihrer privaten Interessen: klassische Konzerte, abenteuerliche Fernreisen (Australien, Südafrika) und nicht zuletzt das Herstellen und Verschenken von Pralinen wurde akribisch geplant und umgesetzt, letzteres sehr zur weihnachtlichen Freude des gesamten Instituts.

Es blieben jedoch auch einige Wünsche unerfüllt: ein Spiel der deutschen Fußball-Nationalmannschaft $\mathrm{zu}$ besuchen, den Vorsitz der AG Gynäkopathologie der DGP zu übernehmen dies und manchen anderen Plan hat die heimtückische, schwere Erkrankung verhindert.

Es war einer der schwersten Momente meines Lebens, Frau Friedrich die maligne Diagnose, mit der keiner von uns wirklich gerechnet hatte, persönlich mitteilen zu müssen. Sie hat diesen Schick- 


\section{Nachrufe}

salsschlag in der ihr eigenen Art als Herausforderung angenommen und der Erkrankung den Kampf angesagt. Sie wollte von Anfang an die maximale Therapie, auch wenn sie genau wusste, wie es um sie stand. Die Gnade des Nichtwissens war ihr als Pathologin nicht gewährt.

Sie ist während des von immer neuen Rückschlägen gekennzeichneten Krankheitsverlaufes zu ihrer wahren menschlichen Größe gelangt. Sobald sie konnte, saß sie wieder am Mikroskop, hat Befunde diktiert und Weiterbildungsassistenten abgenommen. Bis zuletzt hat sie sich auch ihren trockenen Humor bewahrt.

Kurz bevor sie gestorben ist, hat sie noch die folgenden Worte gesagt, die uns bei all dem Kummer, den wir über ihren Tod verspüren, Trost spenden sollen:

"Ich habe mein Leben gelebt, wie ich es wollte!"

Das kann nicht jeder am Ende seiner Lebenszeit von sich sagen.

Wir werden das Andenken an Frau PD Dr. med. habil. Katrin Friedrich immer bewahren und sie nie vergessen.

\section{Gustavo Baretton}

Dresden

\section{Korrespondenzadresse}

Prof. Dr. med. habil. G. Baretton Institut für Pathologie, Universitätsklinikum Carl Gustav Carus, Technische Universität Dresden

Fetscherstraße 74, 01307 Dresden, Deutschland Gustavo.Baretton@uniklinikum-dresden.de

The supplement containing this article is not sponsored by industry. 